\title{
An evaluation of radial and ulnar artery flow characteristics in diabetic patients with carpal tunnel syndrome and the diagnostic value of ultrasonography in these patients
}

\section{Diabetik karpal tünel sendromlu hastalarda radial ve ulnar arterlerin akım karakteristiklerinin değerlendirilmesi ve bu hastalarda ultrasonografinin tanısal değeri}

Ahmet Boyacı ${ }^{1}$, Ahmet Tutoğlư ${ }^{1}$, Nurefşan Boyacı ${ }^{2}$, İrfan Koca ${ }^{3}$, Dilek Şen Dokumacl ${ }^{2}$, Özcan Kocatürk ${ }^{4}$, Mehmet Ali Eren ${ }^{5}$, Ali Şakalar ${ }^{1}$

\begin{abstract}
Objective: This study aimed to research the value of ultrasonography in the diagnosis of carpal tunnel syndrome (CTS) in patients with diabetes mellitus (DM) and to examine the flow characteristics of the radial and ulnar arteries in diabetic patients with CTS.

Methods: A total of 23 diabetic hands diagnosed with CTS from electrophysiological evaluation (DM-CTS), 47 asymptomatic diabetic hands (DM) and 50 healthy hands (C) as the control group were evaluated with high resolution ultrasonography. The median nerve was measured in the crosssectional area (CSA), flattening ratio (FR) and at the level of the carpal tunnel inlet [proximal $(p)]$ and the wrist crease [distal (d)]. The radial and ulnar arteries were evaluated with both hands in a neutral position.
\end{abstract}

Results: In the DM-CTS group, the CSA-p and CSA-d values were statistically signficantly greater compared to the DM and $C$ groups $(p<0.01)$. The FR-p in the DM-CTS group was statistically significantly greater than that of the $C$ groups $\left(p<0.01\right.$ ). In the ROC curve analysis, CSA-p $\geq 9.5 \mathrm{~mm}^{2}$ (AUC 0.84 ; sensitivity $78.3 \%$ and specificity $88 \%$ ) and CSA-d $\geq$ $9.5 \mathrm{~mm}^{2}$ (AUC 0.78 ; sensitivity $73.9 \%$ and specificity $84 \%$ ) were very strong predictors of the DM-CTS hand. In the Doppler examination, no difference was determined between the groups in terms of flow volume, peak systolic velocity, enddiastolic velocity and resistive index measurements of both radial and ulnar arteries $(\mathrm{p}>0.05)$. The radial artery diameter was determined to be statistically significantly greater in the DM-CTS group than the C group $(p<0.05)$.

Conclusion: The median nerve CSA is significantly greater in diabetic CTS patients compared to patients with diabetes only and healthy controls. In the evaluation of CTS in diabetic patients, CSA measured with ultrasonography may be a diagnostic tool. J Clin Exp Invest 2014; 5 (2): 179-185

Key words: Carpal tunnel syndrome, Cross-sectional area, Median nerve, Ultrasonography

\section{ÖZET}

Amaç: Diabetes mellituslu (DM) hastalarda karpal tünel sendromu (KTS) teşhisinde ultrasonografinin değerini ve diabetik KTS'li hastalarda radial ve ulnar arterlerin akım karakteristiklerini araştırmak amaçlanmıştır.

Yöntemler: Elektrofizyolojik değerlendirme ile KTS tesbit edilen 23 el (DM-KTS), asemptomatik 47 el (DM) ve 50 sağlıklı el kontrol grubu (C), yüksek rezolüsyonlu ultrasonografiyle değerlendirildi. Median sinir kesit alanı (CSA) ve düzleşme oranı (FR), karpal tünel girişi [proksimal $(p)$ ] ve bilek kıvrımı [distal (d)] düzeylerden ölçüldü. Her iki el nötral pozisyonda iken radial ve ulnar arterler değerlendirildi.

Bulgular: DM-KTS grubunda, CSA-p ve CSA-d değerleri DM ve $C$ gruplarına göre anlamlı olarak daha büyüktü $(p<0.01)$. FR-p, DM-KTS grubunda C grubuna göre anlamlı olarak daha büyüktü $(p<0.01)$. ROC eğrisi analizinde, CSA-p $\geq 9.5 \mathrm{~mm}^{2}$ (AUC 0.84; duyarlılık 78.3\% and özgüllük $88 \%$ ) ve CSA-d $\geq 9.5 \mathrm{~mm}^{2}$ (AUC 0.78; duyarlılık $73.9 \%$ and özgüllük $84 \%$ ), DM-KTS elin çok güçlü bir prediktörüdür. Doppler incelemesinde her iki radial ve ulnar arter akım volumü, pik sistolik hız, end-diyastolik hız ve rezistif indeks ölçümlerinde gruplar arası farklılık yoktu ( $p>0.05)$. Radial arter damar çapı, DM-KTS grubunda C grubuna göre anlamlı olarak daha büyüktü $(p<0.05)$.

Sonuçlar: Diabetik KTS'li hastalarda diabetli ve sağlıklı kişilere göre median sinir CSA anlamlı olarak büyüktür. Diabetik hastalarda KTS değerlendirilmesinde, ultrasonografiyle ölçülen CSA diagnostik bir araç olabilir.

Anahtar kelimeler: Karpal tünel sendromu, kesit alanı, median sinir, ultrasonografi

\footnotetext{
${ }^{1}$ Harran University Medical School, Department of Physical Medicine and Rehabilitation, Sanliurfa, Turkey,

${ }^{2}$ Harran University Medical School, Department of Radiology, Sanliurfa, Turkey,

${ }^{3}$ Gaziantep University Medical School, Department of Physical Medicine and Rehabilitation, Gaziantep, Turkey

${ }^{4}$ Harran University Medical School, Department of Neurology, Sanliurfa, Turkey,

${ }^{5}$ Department of Endocrinology, Sanliurfa Education and Research Hospital, Sanliurfa, Turkey
}

Correspondence: Ahmet Boyacı,

Harran Üniversitesi Tıp Fakültesi, Fiziksel Tıp Ve Rehabilitasyon Ana Bilim Dalı, Şanlıurfa Email: drboyaci@hotmail.com

Received: 16.02.2014, Accepted: 21.04.2014

Copyright @ JCEI / Journal of Clinical and Experimental Investigations 2014, All rights reserved 


\section{INTRODUCTION}

Carpal tunnel syndrome (CTS) is a widely seen entrapment neuropathy with a prevalence of $2 \%$ in the general population, and has been reported to be seen at a rate of $14 \%$ in diabetes mellitus (DM) patients without diabetic polyneuropathy (DPN) and at $30 \%$ in patients with DPN [1]. The pathophysiology of CTS is not fully known. However, in CTS, median nerve compression in the carpal tunnel is thought to cause functional abnormalities in the early stage and structural abnormalities in advanced stages [2]. Diagnosis is made from clinical examination and electrodiagnostic studies, although nerve conduction studies (NCS) do not give any information about structural abnormalities of the nerve [3]. However, despite the evaluation of clinical symptoms in diabetic hand syndromes which develop in diabetic patients and various comparative NCS tests, the diagnosis of CTS can be difficult [4]. As ultrasonography is painless, easily available and preferred by patients, it has been defined as a non-invasive diagnostic method which can be used in CTS $[3,5]$. A significant correlation has been shown between the median nerves CSA measurements measured with ultrasonography and median nerve conduction abnormalities obtained with electrodiagnostic tests [6].

DM is a risk factor for CTS [7,8]. There are published studies showing a relationship between diagnosis confirmation by ultrasonography and electrodiagnostic results in CTS patients with or without DM $[3,4]$. Changes in flow volumes in hand arteries [9] and impairments in vasomotor activity have also been shown in idiopathic CTS patients [10]. However, to the best of our knowledge there are no studies in literature which have evaluated the characteristics of wrist artery blood flow and ultrasonography and electrodiagnostic findings in DM patients with and without CTS.

Therefore, the aim of this study was to investigate the value of ultrasonography in CTS diagnosis in diabetic patients without DPN and to examine the relationship between the diagnostic confirmation of ultrasonography and electrodiagnostic results. It was also aimed to evaluate the blood flow characteristics of arteries with Doppler ultrasonography in DM patients with and without CTS.

\section{METHODS}

The study initially included 50 patients, diagnosed with Type 2 DM according to the World Health Organization criteria, who presented at the Physical Medicine and Rehabilitation Clinic between Febru- ary 2012 and December 2013 [11]. As a result of the clinical and neurophysiological evaluation, 15 patients with diabetic polyneuropathy were excluded from the study leaving 35 patients with DM in the study. Clinical and electrophysiological evaluation of the DM patients resulted in separation into groups of 23 hands determined with CTS (DM-CTS hands) and 47 asymptomatic hands (DM hands). A control group was formed of 25 healthy individuals (50 hands, $C$ hands). Each hand was evaluated separately in the data analysis.

According to the American Academy of Neurology practice parameters criteria, CTS is defined $[12,13]$ as follows:

1. Increased paresthesia, pain, swelling, weakness and incapacity of the hand when the arm or hand is kept in the same position during sleep or with repeated hand movements and which are reduced with posture changes and shaking of the hand.

2. Sensory deficit in the area of the hand innervated by the median nerve.

3. Hypotrophy or motor deficit of the thenar muscles which are innervated by the median nerve.

4. Positive provocative clinical tests (positive Phalen maneuver and/or positive Tinel's sign).

Diagnosis of CTS is made clinically with the first criteria together with one or more of the other criteria.

The electrophysiological diagnosis of CTS was based on median nerve distal sensory latency $>3.4$ $\mathrm{ms}$, median nerve distal motor latency over $4.2 \mathrm{~ms}$ [14]; and a difference between median and ulnar nerve distal sensory latencies $>0.4 \mathrm{~ms}$ [15].

Patients were excluded if they had neurological, rheumatological or nephrological diseases, pregnancy, previous CTS surgery, or a history of forearm fracture, steroid injection into the carpal tunnel within the previous three months, splint use, or a history of malignancy, cervical radiculopathy or diabetic polyneuropathy in the electrophysiological examination. The Institutional Ethics Committee approved the study protocol and all subjects provided written informed consent.

Grey scale and Doppler sonography were performed using a Logic 7 (GE Healthcare, Milwaukee, WI, USA) ultrasound machine and a high-resolution $12-\mathrm{MHz}$ probe. All measurements were performed with the same device by a single radiologist blinded to the subjects' clinical and laboratory results. The ultrasonography and Doppler evaluations were per- 
formed in the same session. The patient was seated facing the doctor with the forearm on the knees, the palm supine, and fingers semi-extended in the neutral position. The transducer was placed directly on the patient's skin with gel. For the transverse scan, the probe was kept directly perpendicular to the long axis of the median nerve in order to ensure that the area measured reflected a cross-sectional area (CSA) (Figure 1). The CSA and flattening ratio (FR, defined as the ratio of the major axis of the median nerve to its minor axis) were measured at the tunnel inlet (proximal) and $1 \mathrm{~cm}$ distal to the wrist crease (distal). The "tunnel inlet" referred to the level immediately deep to the proximal edge of the flexor retinaculum. The thickness of the flexor retinaculum was also measured.

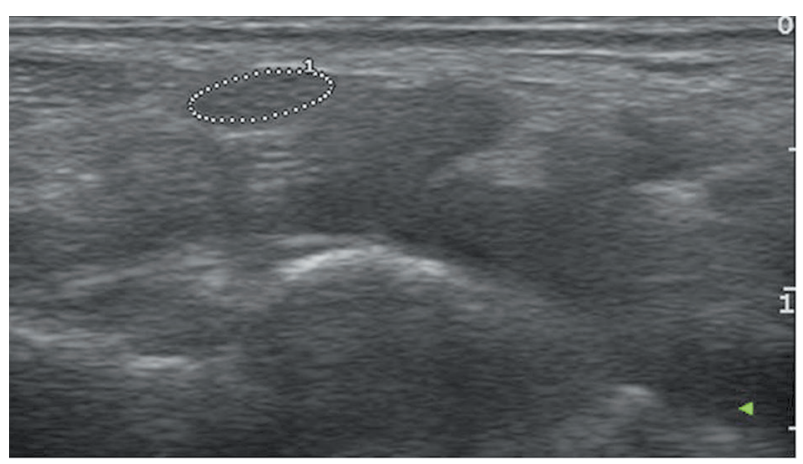

Figure 1. Transverse ultrasonographic image is at the proximal carpal tunnel at the level of the pisiform, showing the cross-sectional area measurement of the median nerve.

Doppler imaging was used to evaluate the resistive index (RI), peak systolic velocity (PSV), enddiastolic velocity (EDV), vascular diameter, and flow volume (FV) in the radial and ulnar arteries. FV was calculated by artery diameter measurement using the area below the spectral waveform. RI was defined as the difference between the peak systolic and end-diastolic flow velocities divided by the peak systolic flow velocity. Doppler imaging was used to guide the placement of the spectral Doppler gate and to estimate the beam-to-vessel angle. The Doppler angle was maintained at $60^{\circ}$ throughout the examinations. The blood flow parameters were compared between the groups.

\section{Statistical analysis}

Statistical analyses were carried out using SPSS 18.0 for Windows (PASW Statistics for Windows, SPSS Inc., Chicago, IL, USA). Distributions of parametric variables were evaluated using the one-sample Kolmogorov- Smirnov test. One-way analysis of variance (ANOVA) with Bonferroni post hoc correction was used to compare the differences among groups. For intergroup comparisons of categorical variables, cross-table statistics were given, and a Chi-square test was used to assess the level of significance. ROC curve analysis was used to determine the CSA value most predictive of CTS hands. Pearson's or Sperman's correlation test was used to determine the relationships between variables. Linear regression analysis was performed to identify independent predictors of CSA. All demographic and quantitative data were expressed as mean \pm $S D$. Differences with $p$ values of $<0.05$ were considered to be statistically significant, and all results are expressed with a $95 \%$ confidence interval.

\section{RESULTS}

The demographic data of the study participants are shown in Table 1. There were 23 hands in the DMCTS group, 47 hands in the DM group and 50 hands in the $\mathrm{C}$ group. No statistically significant difference was determined between the 3 groups in terms of body mass index (BMI), age, gender or occupation $(p>0.05)$.
Table 1. Baseline characteristics of the study participants

\begin{tabular}{lcccc}
\hline & $\begin{array}{c}\text { DM-CTS-hands } \\
(\mathbf{n = 2 3})\end{array}$ & $\begin{array}{c}\text { DM-hands } \\
(\mathbf{n = 4 7 )}\end{array}$ & $\begin{array}{c}\text { C-hands } \\
(\mathbf{n = 5 0 )}\end{array}$ & $\mathbf{p}$ \\
\hline Age & $50.73 \pm 11.71$ & $53.65 \pm 8.60$ & $50.44 \pm 9.83$ & 0.234 \\
Female, n (\%) & $16(69.6)$ & $26(55.3)$ & $34(68)$ & 0.341 \\
BMI & $32.47 \pm 7.22$ & $32.73 \pm 5.73$ & $33.94 \pm 5.22$ & 0.485 \\
Duration of DM (years) & $11.13 \pm 7.33$ & $7.10 \pm 7.44$ & & \\
HbA1c & $8.45 \pm 1.41$ & $7.91 \pm 1.87$ & & \\
Occupational status & & & & \\
Housewife, $\mathrm{n}$ & 14 & 26 & 32 & \\
Working, $\mathrm{n}$ & 2 & 10 & 12 & 0.254 \\
Retired, $\mathrm{n}$ & 7 & 11 & 6 & \\
\hline
\end{tabular}

BMI: Body mass index, CTS: Carpal tunnel syndrome, DM: Diabetes mellitus 
Table 2. Parameters of ultrasonography among the groups

\begin{tabular}{lcccc}
\hline & $\begin{array}{c}\text { DM-CTS } \\
\text {-hands } \\
(\mathbf{n = 2 3})\end{array}$ & $\begin{array}{c}\text { DM-hands } \\
(\mathbf{n = 4 7 )}\end{array}$ & $\begin{array}{c}\text { C-hands } \\
(\mathbf{n = 5 0 )}\end{array}$ & $\begin{array}{c}\text { ANOVA } \\
\mathbf{p}\end{array}$ \\
\hline FR-p & $2.40 \pm 0.54$ & $2.18 \pm 0.51$ & $2.05 \pm 0.31^{\mathrm{c}}$ & $\mathbf{0 . 0 1 0}$ \\
FR-d & $2.31 \pm 0.58$ & $2.03 \pm 0.54$ & $2.06 \pm 0.47$ & 0.103 \\
CSA-p $\left(\mathrm{mm}^{2}\right)$ & $13.30 \pm 4.87$ & $9.38 \pm 2.54^{\mathrm{b}}$ & $8.26 \pm 2.60^{\mathrm{c}}$ & $<\mathbf{0 . 0 0 1}$ \\
CSA-d $\left(\mathrm{mm}^{2}\right)$ & $14 \pm 6.14$ & $9.45 \pm 3.00^{\mathrm{b}}$ & $8.62 \pm 2.39^{\mathrm{c}}$ & $\mathbf{0 . 0 1 5}$ \\
FRT $(\mathrm{mm})$ & $1.80 \pm 0.45$ & $1.74 \pm 0.32$ & $1.57 \pm 0.32^{\mathrm{a}}$ & $\mathbf{0 . 0 1 5}$ \\
\hline
\end{tabular}

CSA: Cross-sectional area, C: Control, CTS: Carpal tunnel syndrome, DM: Diabetes mellitus, d: Distal, FR: Flattening ratio, FRT: Flexor retinaculum thickness, p: Proximal

a $p<0.05$ compared with CTS-DM hands, bp $<0.01$ compared with CTS-DM hands, $\mathrm{cp}<0.01$ compared with CTSDM hands by Bonferroni post hoc correction test.

The comparison of ultrasonographic parameters between the groups is shown in Table 2. In the comparison between the groups, there was a significant difference in the median nerve CSA proximal (p) and the CSA distal (d). The CSA-p and CSA-d in the DM-CTS group were statistically significantly greater than those of the DM and C groups $(p<0.01)$.

The results of the Doppler evaluation of the subjects' hands which were evaluated in a neutral position are shown in Table 3. A statistically significant difference was determined between the groups in respect of the radial artery diameter $(p=0.002)$. The radial artery diameter of the DM-CTS group was statistically significantly greater than that of the C group $(p<0.05)$.

The ROC curve analysis of the DM-CTS group is shown in Figure 2. A positive correlation was determined in CSA-p and CSA-d with the duration of the disease. A positive correlation was also found between CSA-p and ulnar artery RI (Table 4).

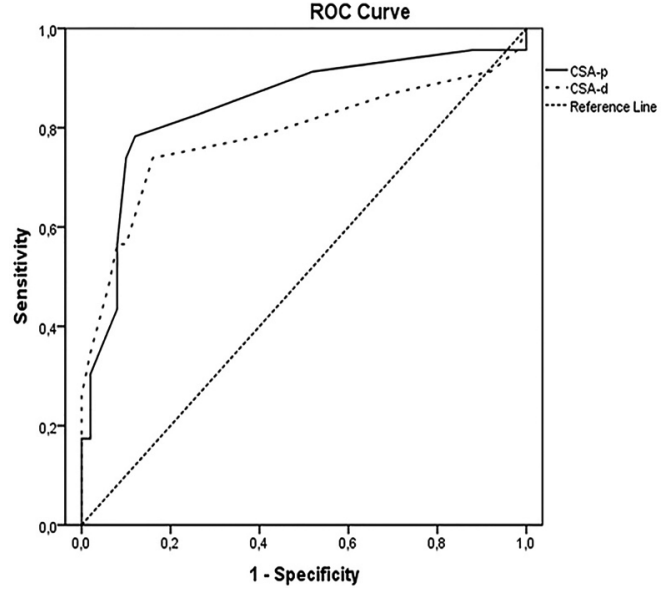

Figure 2. The ROC curve analysis of CSA-p (black line) and CSA-d (dot line) for CTS in DM patients. CSA-p $\geq 9.5$ $\mathrm{mm}^{2}$ (AUC 0.84 ; sensitivity $78.3 \%$ and specificity $88 \%$ ) and CSA-d $\geq 9.5 \mathrm{~mm}^{2}$ (AUC 0.78 ; sensitivity $73.9 \%$ and specificity $84 \%$ ) are very strong predictors of DM-CTS hands.
Table 3. Doppler sonography assessments of flow volume, diameter, peak systolic velocity, enddiastolic velocity, and resistive index of radial and ulnar arteries at neutral positions

\begin{tabular}{llcccc}
\hline Arteries & & $\begin{array}{c}\text { DM-CTS-hands } \\
(\mathbf{n}=\mathbf{2 3})\end{array}$ & $\begin{array}{c}\text { DM-hands } \\
(\mathbf{n}=\mathbf{4 7})\end{array}$ & $\begin{array}{c}\text { C-hands } \\
(\mathbf{n}=\mathbf{5 0})\end{array}$ & $\mathbf{p}$ \\
\hline \multirow{3}{*}{ Radial artery } & $\mathrm{FV}(\mathrm{mL} / \mathrm{s})$ & $39.93 \pm 16.72$ & $39.76 \pm 21.19$ & $39.37 \pm 24.93$ & 0.993 \\
& $\mathrm{PSV}(\mathrm{cm} / \mathrm{s})$ & $59.46 \pm 14.46$ & $64.78 \pm 20.15$ & $60.14 \pm 13.31$ & 0.291 \\
& EDV $(\mathrm{cm} / \mathrm{s})$ & $12.81 \pm 7.38$ & $15.33 \pm 10.14$ & $13.67 \pm 6.55$ & 0.424 \\
& Diameter $(\mathrm{mm})$ & $2.51 \pm 0.46$ & $2.31 \pm 0.35$ & $2.16 \pm 0.40^{\mathrm{a}}$ & $\mathbf{0 . 0 0 2}$ \\
& $\mathrm{RI}$ & $0.77 \pm 0.11$ & $0.77 \pm 0.12$ & $0.78 \pm 0.08$ & 0.906 \\
\hline \multirow{3}{*}{ Ulnar artery } & $\mathrm{FV}(\mathrm{mL} / \mathrm{s})$ & $38.70 \pm 28.86$ & $47.74 \pm 41.90$ & $33.87 \pm 16.19$ & 0.089 \\
& $\mathrm{PSV}(\mathrm{cm} / \mathrm{s})$ & $57.09 \pm 20.87$ & $66.37 \pm 23.50$ & $60.37 \pm 12.07$ & 0.116 \\
& EDV $(\mathrm{cm} / \mathrm{s})$ & $13.73 \pm 9.28$ & $18.24 \pm 12.11$ & $13.89 \pm 6.16$ & 0.050 \\
& Diameter $(\mathrm{mm})$ & $2.29 \pm 0.44$ & $2.24 \pm 0.46$ & $2.08 \pm 0.32$ & 0.061 \\
& $\mathrm{RI}$ & $0.70 \pm 0.37$ & $0.74 \pm 0.13$ & $0.77 \pm 0.07$ & 0.084 \\
\hline
\end{tabular}

C: Control, CTS: Carpal tunnel syndrome, DM: Diabetes mellitus, FV: Flow Volume, PSV: Peak Systolic Velocity, EDV: End-Diastolic Velocity, RI: Resistive Index

a $p<0.05$ compared with CTS-DM hands by Bonferroni post hoc correction test. 
Table 4. Bivariate and multivariate regression analysis for predicting CSA in all DM patients

\begin{tabular}{|c|c|c|c|c|c|c|c|c|}
\hline & \multicolumn{4}{|c|}{ CSA-p } & \multicolumn{4}{|c|}{ CSA-d } \\
\hline & $r$ & $\mathrm{p}$ & $\beta$ & $p$ & $r$ & $\mathrm{p}$ & $\beta$ & $\mathrm{p}$ \\
\hline Age & -0.125 & 0.304 & & & -0.146 & 0.228 & & \\
\hline Gender & 0.107 & 0.380 & & & 0.101 & 0.407 & & \\
\hline $\mathrm{BMI}$ & 0.092 & 0.448 & & & -0.013 & 0.913 & & \\
\hline Duration of DM & 0.376 & 0.001 & 0.286 & 0.01 & 0.291 & 0.015 & 0.238 & 0.04 \\
\hline $\mathrm{HbA} 1 \mathrm{c}$ & -0.06 & 0.624 & & & -0.07 & 0.538 & & \\
\hline FRT (mm) & 0.093 & 0.444 & & & 0.004 & 0.972 & & \\
\hline $\mathrm{rFV}(\mathrm{mL} / \mathrm{s})$ & -0.183 & 0.130 & & & -0.117 & 0.336 & & \\
\hline $\mathrm{rPSV}(\mathrm{cm} / \mathrm{s})$ & -0.114 & 0.346 & & & -0.177 & 0.143 & & \\
\hline $\mathrm{rEDV}(\mathrm{cm} / \mathrm{s})$ & -0.075 & 0.536 & & & -0.076 & 0.534 & & \\
\hline r diameter (mm) & -0.086 & 0.478 & & & -0.100 & 0.410 & & \\
\hline $\mathrm{rRI}$ & -0.029 & 0.809 & & & -0.028 & 0.820 & & \\
\hline $\mathrm{uFV}(\mathrm{mL} / \mathrm{s})$ & 0.017 & 0.892 & & & 0.011 & 0.929 & & \\
\hline uPSV $(\mathrm{cm} / \mathrm{s})$ & 0.024 & 0.846 & & & -0.058 & 0.639 & & \\
\hline $\mathrm{uEDV}(\mathrm{cm} / \mathrm{s})$ & -0.152 & 0.210 & & & -0.165 & 0.172 & & \\
\hline u diameter $(\mathrm{mm})$ & 0.095 & 0.434 & & & 0.142 & 0.240 & & \\
\hline uRI & 0.248 & 0.038 & 0.309 & 0.009 & 0.190 & 0.116 & & \\
\hline
\end{tabular}

BMI: Body mass index, CSA: Cross-sectional area, DM: Diabetes mellitus, d: Distal, EDV: End-Diastolic Velocity, FRT: Flexor retinaculum thickness, FV: Flow Volume, PSV: Peak Systolic Velocity, RI: Resistive Index, p: Proximal, r: Radial artery, u: Ulnar artery, $\beta$ : Regression coefficient.

\section{DISCUSSION}

In the current study, the median nerve CSA-p and CSA-d were found to be significantly greater in the diabetic patients with CTS compared to the diabetic patients and the control group. The thickness of the flexor retinaculum of the diabetic patients with CTS was found to be greater than that of the control group. The cut-off value of CSA-p and CSA-d for CTS confirmation was more than $9.5 \mathrm{~mm}^{2}$ in diabetic patients. In diabetic patients a positive correlation was found between CSA-p and CSA-d, the duration of the disease and ulnar artery RI values. In addition, the radial artery diameter of DM-CTS patients was found to be significantly greater than that of the healthy control group.

In clinical practice, even if electrodiagnostic tests are applied to diabetic patients, it is difficult to differentiate CTS from other neuropathic syndromes [1]. CSA measurements made with ultrasonography play a complementary role in the diagnosis of CTS and are considered to have made this a valu- able diagnostic method [16]. Previous studies have shown significant differences in median nerve CSA measurements between idiopathic CTS patients and healthy controls $[5,16]$. In a study comparing idiopathic, diabetic and DPN patients with CTS and healthy controls, the CSA of the idiopathic, diabetic and DPN patients with CTS was found to be greater than that of the healthy controls. In that study, it was also found that the CSA of the diabetic patients with CTS was greater than that of idiopathic CTS patients [4]. In a recent study, the CSA of diabetic and non-diabetic CTS patients was determined to be greater than that of healthy controls, but there was no difference between diabetic CTS patients and idiopathic CTS patients. In the same study, the CSA measured in the distal of the flexor retinaculum (CSA-d) was found to be significantly greater than that of the diabetes group [3]. In the current study, the median nerve CSA-p and CSA- $d$ of the diabetic patients with CTS were found to be greater than those of the diabetic and healthy individuals. 
Many factors are known to be related to CTS, such as mechanical and ischemic factors, external epineural and perineural thickening and fibrosis [17]. Local widening of the median nerve CSA may be explained by all these factors. In diabetic patients, focal widening of the median nerve CSA is seen particularly at the level of the tunnel inlet. The polyol pathway, glycation and pro-inflammatory reactions are known to be related to diabetic peripheral nerve injury [18] and reduced capillary density and myelinated nerve fibers in diabetic patients [19]. CSA widening may be caused by a predisposition to CTS. In the current study, the duration of the disease in diabetic patients was seen to be an independent risk factor of CSA widening. In addition, as there were no idiopathic CTS patients in the current study, how much biological response to compression and diabetic peripheral nerve injury contributed to CSA widening in diabetic patients could not be evaluated.

A previous study has shown that increased median nerve CSA is a highly significant predictor of non-diabetic CTS [20]. Studies have reported critical CSA values of $9-14 \mathrm{~mm}^{2}$ as predictive of CTS in non-diabetic groups [21]. In a study which excluded DPN patients, in the confirmation of CTS in diabetic and non-diabetic CTS patients, the CSA measurement from the wrist crease was shown to be more than $13 \mathrm{~mm}^{2}$ in both groups [3]. In a study by Chen et al, the CSA cut-off values measured from the tunnel inlet, the wrist crease and the tunnel outlet were $15.3 \mathrm{~mm}^{2}, 13.4 \mathrm{~mm}^{2}$ and $10 \mathrm{~mm}^{2}$ respectively in the diabetic CTS group and $14 \mathrm{~mm}^{2}, 12.5 \mathrm{~mm}^{2}$ and 10.5 $\mathrm{mm}^{2}$ respectively in the DPN CTS group [4]. In the current study, the CSA cut-off value measured at the level of the tunnel inlet and the wrist crease was found to be $9.5 \mathrm{~mm}^{2}$ at both levels in the diabetic CTS group.

In a study comparing the arterial flow parameters of CTS patients with those of healthy controls, a significant increase was seen in the radial and ulnar artery flows of the CTS patients [9]. It was suggested in that study that the increased arterial flow could be associated with substance $\mathrm{P}$ or local inflammatory response to sympathoparalytic vasodilation in CTS patients [9]. Another reason for increased arterial blood flow in CTS may be impairment in the autonomic control of local blood perfusion in the distal area innervated by the median nerve associated with median nerve compression [22]. A recent study which used Doppler ultrasonography showed impaired vasomotor activity in CTS patients [10]. In another study in which median nerve circulation was evaluated with dynamic MRI in CTS patients, it was shown that the changes created in CTS were associated with chronic hypoxia due to the irregular circulation in CTS rather than nerve compression [23]. In the current study, no significant difference was found in the flow volumes of all three groups. However the radial artery diameter was determined to be greater in the diabetic CTS patients than in the healthy controls. This may have been due to impaired vasomotor activity in the CTS group. In addition, a positive correlation was found between the CSA and the ulnar artery RI values in the diabetic patients. RI reflects vessel compliance according to changes in systemic blood pressure. Increased $\mathrm{RI}$ reflects reduced vascular compliance [24]. In the current study, reduced ulnar artery compliance was shown by the increased CSA.

There were some limitations to the current study. First was that the number of cases was low despite several confounding factors, especially in the diabetic group. Secondly, as DPN patients were excluded from the study, the results may not reflect the results of all diabetic patients with CTS. Thirdly, as patients with idiopathic CTS were not compared with diabetic CTS patients, the role of diabetes in the changes which occurred could not be evaluated.

In conclusion, median nerve CSA measured with ultrasonography can be a diagnostic modality in the evaluation of CTS. The median nerve widening which develops associated with median nerve axonal degeneration and demyelinisation can be determined by calculating the CSA. The changes determined on Doppler ultrasonography can be related to clinical findings such as nocturnal pain, swelling and changes. To confirm the relationship between blood flow and sympathetic innervation, there is a need for further studies to examine blood flow parameters at the same time as monitorization of the sympathetic nerves of the hand.

\section{REFERENCES}

1. Perkins BA, Olaleye D, Bril V. Carpal tunnel syndrome in patients with diabetic polyneuropathy. Diabetes Care 2002;25:565-569.

2. Jablecki CK, Andary MT, So YT, et al. Literature review of the usefulness of nerve conduction studies and electromyography for the evaluation of patients with carpal tunnel syndrome. AAEM Quality Assurance Committee. Muscle Nerve 1993;16:1392-1414.

3. Tsai NW, Lee LH, Huang CR, et al. The diagnostic value of ultrasonography in carpal tunnel syndrome: a comparison between diabetic and non-diabetic patients. BMC Neurol 2013;13:65-72. 
4. Chen SF, Huang CR, Tsai NW, et al. Ultrasonographic assessment of carpal tunnel syndrome of mild and moderate severity in diabetic patients by using an 8-point measurement of median nerve cross-sectional areas. BMC Med Imaging 2012;12:15-24.

5. Visser LH, Smidt MH, Lee ML. High-resolution sonography versus EMG in the diagnosis of carpal tunnel syndrome. J Neurol Neurosurg Psychiatry 2008;79:63-67.

6. El Miedany YM, Aty SA, Ashour S. Ultrasonography versus nerve conduction study in patients with carpal tunnel syndrome: substantive or complementary tests? Rheumatology (Oxford) 2004;43:887-895.

7. Becker J, Nora DB, Gomes I, et al. An evaluation of gender, obesity, age and diabetes mellitus as risk factors for carpal tunnel syndrome. Clin Neurophysiol 2002;113:1429-1434.

8. Uzkeser H, Karatay S, Alkan Melikoğlu M. Levels of endocrine hormones and lipids in male patients with carpal tunnel syndrome. Dicle Medical Journal 2011;38:427-431.

9. Ozcan HN, Kara M, Ozcan F, et al. Dynamic Doppler evaluation of the radial and ulnar arteries in patients with carpal tunnel syndrome. AJR Am J Roentgenol 2011;197:817-820.

10. Ghasemi-Esfe AR, Morteza A, Khalilzadeh O, Mazloumi M, Ghasemi-Esfe M, Rahmani M. Color Doppler ultrasound for evaluation of vasomotor activity in patients with carpal tunnel syndrome. Skeletal Radiol 2012;41:281-286.

11. American Diabetes Association: Diagnosis and classification of diabetes mellitus. Diabetes Care 2006;35:64-71.

12. You H, Simmons Z, Freivalds A, Kothari MJ, Naidu $\mathrm{SH}$. Relationships between clinical symptom severity scales and nerve conduction measures in carpal tunnel syndrome. Muscle Nerve 1999;22:497-501.

13. Keith MW, Masear V, Chung K, et al. Diagnosis of carpal tunnel syndrome. J Am Acad Orthop Surg 2009;17:389-396.
14. Jackson DA, Clifford JC. Electrodiagnosis of mild carpal tunnel syndrome. Arch Phys Med Rehabil 1989;70:199-204.

15. Uncini A, Lange DJ, Solomon M, Soliven B, Meer $J$, Lovelace RE. Ring finger testing in carpal tunnel syndrome: a comparative study of diagnostic utility. Muscle Nerve 1989;12:735-741.

16. Chen SF, Lu CH, Huang CR, et al. Ultrasonographic median nerve cross-section areas measured by 8-point "inching test" for idiopathic carpal tunnel syndrome: a correlation of nerve conduction study severity and duration of clinical symptoms. BMC Med Imaging 2011;11:22-30.

17. Mackinnon SE. Pathophysiology of nerve compression. Hand Clin 2002;18:231-241.

18. Yagihashi S. Recent advances in clinical practice and in basic research on diabetic neuropathy]. Brain Nerve 2011;63:571-582.

19. Thomsen NO, Mojaddidi M, Malik RA, Dahlin LB. Reduced myelinated nerve fibre and endoneurial capillary densities in the forearm of diabetic and nondiabetic patients with carpal tunnel syndrome. Acta Neuropathol 2009;118:785-791.

20. Hunderfund AN, Boon AJ, Mandrekar JN, Sorenson EJ Sonography in carpal tunnel syndrome. Muscle Nerve 2011;44:485-491.

21. Seror P. Sonography and electrodiagnosis in carpal tunnel syndrome diagnosis, an analysis of the literature. Eur J Radiol 2008;67:146-152.

22. Jordan SE, Greider JL, Jr. Autonomic activity in the carpal tunnel syndrome. Orthop Rev 1987;16:165169.

23. Sugimoto H, Miyaji N, Ohsawa T (1994) Carpal tunnel syndrome: evaluation of median nerve circulation with dynamic contrast-enhanced MR imaging. Radiology 1994;190:459-466.

24. Şen TA, Bükülmez A, Köken R, et al. Tip 1 Diabetes Mellituslu Çocukların Retinal Doppler Ultrasonografi Bulguları ve Homosistein Düzeyleri. Güncel Pediatri 2008;6:19-25. 